\title{
INTERCULTURAL COMPETENCE IN TEACHING AND LEARNING FOREIGN LANGUAGES
}

\author{
Georgeta OBILIŞTEANU, Brânduşa-Oana NICULESCU \\ “Nicolae Bălcescu" Land Forces Academy, Sibiu, Romania \\ pusa_obi@hotmail.com, branducosma@yahoo.com
}

\begin{abstract}
There has been an increase in the importance of the cultural aspect in teaching and learning foreign languages, and teachers nowadays are supposed to stimulate the acquisition and development of intercultural competence in their students. Foreign language teaching and learning should be regarded from an intercultural perspective. The foreign language classes can be the link between the two cultures by which students have the opportunity to discover other values, mentalities, and facets of life. In doing this, a new vision should be taken into consideration, in which the teacher naturally and harmoniously combines the linguistic and cultural elements in the educational process during all types of lessons, irrespective of the topic being dealt with, or whether they focus on grammar or vocabulary issues. The culture and civilization notions must not be regarded separately, but should be integrated in the activities meant to develop the four language skills. This paper highlights the role of foreign language teachers in developing intercultural competence, the didactic activities used in forming the cadets' intercultural competence, pointing to the way in which this competence is achieved in the military higher education environment as well.
\end{abstract}

Keywords: intercultural competence, military higher education, teaching and learning foreign languages, didactic activities.

\section{Introduction}

In the last two decades, the Romanian armed forces have taken part in an increasing number of diverse military operations, including peace-making, peacekeeping, search and rescue, humanitarian, medevac tasks. Since within these operations the military personnel come into contact and have to work side by side with the staff pertaining to other cultures, they should be educated and trained in advance with regard to the cultural differences they will encounter. Therefore, our cadets need to be endowed with the necessary intercultural competence that will ensure the efficiency of the multinational operations.

In recent years, there have been given many definitions of intercultural competence. According to UNESCO, intercultural competence represents "having adequate relevant knowledge about particular cultures, as well as general knowledge about the sorts of issues arising when members of different cultures interact, holding receptive attitudes that encourage establishing and maintaining contact with diverse others, as well as having the skills required to draw upon both knowledge and attitudes when interacting with others from different cultures." [1] Another relevant definition belongs to the American researcher Deardorff who states that intercultural competence is "the ability to develop targeted knowledge, skills and attitudes that lead to visible behaviour and communication that are both effective and appropriate in intercultural interactions."[2] Hence, in our view, the concept of intercultural competence refers to an 
individual's ability to adapt his/her attitude, behaviour, knowledge in linguistically and culturally complex circumstances, the manner in which people from different cultures and having diverse backgrounds successfully interact with others.

Due to the fact that language and culture are closely related, the teaching and learning of foreign languages is an intercultural dialogue during which the terrain for a possible encounter with a different world is prepared and the negative consequences of the impact of the cultural shock produced by this encounter are avoided. The foreign language classes provide the conditions for analysing and interpreting the existing differences between the native culture and the foreign one, leading to the discovery and understanding of these differences not only through the simple clichés that have been formed on other nationalities over the years, but also through a positive attitude towards a foreign interlocutor and openness towards the world he/she comes from.

\section{The role of foreign language teachers in developing intercultural competence}

Once the dimension of culture has been recognized to language, the foreign language teachers have been experiencing a period of great change. The Common European Framework for Foreign Languages (CEFFL) [3] highlights the acquisition of cultural aspects in the process of teaching and learning a foreign language, making it a mandatory requirement not only from the point of view of communicating efficiently, but also from an active and constructive perspective that can be further applied at a social, professional and cultural level.

The foreign language classes ought to be the link between the two cultures by which students have the opportunity to discover other values, mentalities and realities of life. Moreover, the intercultural competence described and analysed by the CEFFL is insisted upon as a major objective of a foreign language. Acquiring the linguistic competence during the foreign language class is important, but no longer sufficient. Language does not represent a simple tool for communication consisting in the factual transmission of information, but a cultural treasure incorporating the history and evolution of a people that throughout its existence has gathered attitudes, values, mentalities, beliefs, behavioural patterns, a whole existential philosophy. Thus, the history of a people, the social norms and foundations of a society are essential factors in understanding the culture and civilization of that people. In this context, the individuals learning a foreign language must be aware that this process implies the appropriate understanding and interpretation of the ethno-socio-cultural elements specific to the target language It is important to underline the fact that intercultural competence consists of knowledge, skills and attitudes, along with the values and beliefs an individual cherishes due to having a particular social identity. In developing intercultural competence, the foreign language teacher has to pay equal attention to these three components.

Students definitely need some factual information about the specific culture they will interact with, but this has to be complemented by a wide range of topics that cover as much information about that culture as possible. An important role of the teacher is that of developing the students' intercultural attitudes by arousing their interest, curiosity and openness to another culture. Besides knowledge and attitudes, the students must also be endowed with the skills of discovery and interaction, of comparing and interpreting authentic documents from another culture and of relating them to events from their own. [4] Therefore, the role of the foreign language teacher is to develop some knowledge of a particular culture, as well as the necessary skills and attitudes. Once the necessary knowledge and skills have been acquired by the students, there will be a change in their attitudes and sensitivity to the social patterns, norms, beliefs and values of a 
different country.

In this way, with the aid of the foreign language teachers, our cadets will be able to properly interact in professional contexts, differentiating between cultural subtleties and adjusting their responses and manifestations to the given situation.

\section{Didactic activities used in forming cadets' intercultural competence during foreign language classes}

In coming in contact with a different culture, students should value the foreign language and culture, so that they may acquire a positive attitude. The role of the foreign language teachers is to employ appropriate didactic strategies that generate a positive mindset, crucial for understanding and evaluating individuals coming from a different culture.

Since cadets learning a foreign language must appropriately understand and interpret the ethno-socio-cultural elements specific to the target language, foreign language teachers in the military system of education should design a series of didactic activities to allow learners to have debates on what they already know about the target culture. After having been provided with some factual information on the life style, habits, customs, behaviours, traditions and beliefs held by the inhabitants of the foreign country, students should be encouraged to make comparisons and establish similarities and differences between the foreign cultural patterns and their own.

Among the didactic activities that can be fruitfully used in order to activate the background information the students have about the target culture, we must mention simulations and role-plays. [5] This kind of learning experience will develop selfawareness and make them more subtle observers of other cultural behaviours. The changes produced in the way they perceive other countries will also determine positive changes in the attitudes they will have in their interactions with intercultural speakers. Becoming knowledgeable on the target culture, they will be more tolerant towards the differences and be able to deal with the everyday situations they are likely to encounter in a foreign country or to handle in a professional context. In fact, a change in attitude and action is ultimately the main goal of intercultural education, which the foreign language teachers should bear in mind.

In providing the factual information, a variety of authentic materials can be used, including reading passages, tape recordings, visuals, such as photographs, diagrams, maps, charts, tables, etc. In using an authentic document, teachers should make sure the students are provided with its context, that is the type, date, and place of publication, the intended audience, the author's political, social, religious or cultural outlook, as well as the intention the author had in mind - to convince the readers of the rightness of his/her ideas, to produce a change in the readers' mind, to amuse, to criticize or to encourage a certain behavioural pattern.

These authentic resources are always to be approached critically. In order to challenge the cadets, the foreign language teachers should bring together texts and audio/visual materials which offer contrasting points of view.

The role of the teacher is to help learners analyse the strange information they get and make it familiar by making sure that the learning experience is a positive one, not a cultural encounter that overwhelms them, influencing them negatively. The desired change in attitude and reconsideration of values take place in a positive working environment. Teachers are responsible for creating it so that their students can develop the other intercultural components which will help them to successfully interact with people of other cultures and identities.

Besides simulations and role plays other types of activities are proposed by Lázár et al. [6] for shaping intercultural communicative competence: brainstorming used to identify the way in which students relate to certain social and cultural concepts; oral presentations of different 
customs and traditions of the foreign culture; case studies meant to make learners aware of the cultural similarities and differences as well as to their relevance for proper communication; group projects to develop the students communicative competence and questionnaires to offer them concrete information on different cultures.

It is important to emphasize that the intercultural perspective in teaching foreign languages focuses on the cultural dimension of language. The complex relationship between language and culture can fruitfully be exploited as a means of promoting understanding and accepting cultural diversity.

\section{Contribution of teaching foreign languages to shaping intercultural competence in the military higher education environment}

The training of the Land Forces cadets has to take into consideration the intercultural aspect of the communication competence. Teachers must translate the intercultural competence into clear learning outcomes and correlate them with a series of didactic strategies and activities that will focus on the cadets' acquiring the necessary intercultural knowledge, skills and attitudes, thus allowing them to interact and take appropriate action depending on the situation they will be confronted with within the military operations they will take part in.

We underline the fact that the acquisition of this type of competence should be based on a holistic academic system of education and viewed from an interdisciplinary perspective in which all the subject matters, especially the social and humanistic sciences, are culturally-oriented from the point of view of the content teachers introduce in the syllabus, trying to address not only the knowledge component of the intercultural competence, but also the components of skills and attitudes.

Among the disciplines that can mould these skills, foreign languages play the most important role because culture is inextricably linked to language. The social and cultural elements cannot be correspondingly approached, understood and interpreted without mastering a certain level of language proficiency. In the context of developing intercultural competence, language proficiency is of paramount importance.

Being mindful of the changes that are currently occurring in the military context, hence of the various missions the Land Forces cadets will have to take part in and work within the multinational formations on the international theatres of operation, the English language teachers have introduced in the syllabus culturallyoriented topics that respond to the new needs. In coming in contact with the target culture, at first they may categorically reject the new social and cultural elements, but then their whole attitude changes, becoming tolerant and respectful to the new culture, understanding and critically interpreting the similarities and differences they observe.

Within the didactic activities in class, the teachers go beyond language acquisition, so that learners absorb not only the information on the British and American culture, but also get sensitive to the cultural differences that might have an impact in today's military environment. In order to develop their intercultural communication competence, cadets are required to analyse the ideas in the written documents, to express opinions, to compare and summarize, to make hypotheses, to negotiate, to deliver oral presentations and give briefings.

Moreover, they are taught to pay attention and not disregard the non-verbal communication elements. The ability to correctly decode and interpret the nonverbal signs will prove to be crucial during the international military operations. They must be aware of the fact that, when posted abroad, soldiers will have to adopt the mindset that will make them understand the potentially far-reaching effects of a single gesture, word, or action. In order to win the 
hearts and minds of the local community, they must display intercultural skills of the highest order.

The gap between different cultures has also been bridged by the opportunity offered in our academy to the cadets of benefiting from the experience of other military teachers, instructors and students by joining the common training and mobility programs organized through the Erasmus + , the European Initiative for the Exchange of Young Officers ("Military Erasmus") and iMAF programs. Our cadets have so far attended the courses or taken part in the military sessions held in around 20 partner universities (for example, Tereziana Military Academy, Wiener Neustadt, Austria; Royal Military Academy, Brussels, Belgium; "Vasil Levski" National Military University, Veliko Tarnovo, Bulgaria; University of Defence, Brno, Czech Republic; "General Tadeusz Kosciuszko", Military Academy of Land Forces, Wroclaw, Poland and National University of Public Service, Budapest, Hungary) within these programs.

\section{Conclusions}

Since language is a linguistic and social phenomenon, the intercultural perspective supposes a communication competence based on the interlocutors' ability to adequately identify and use the social and cultural aspects within the linguistic interactions. From the point of view of understanding, the student must have the competences necessary for correctly identifying, recognizing and interpreting the interlocutor' $s$ attitudes and behaviours involving gestures, historical or cultural elements.

Therefore, learning a foreign language must prepare the student for real life situations, for various intercultural changes and experiences. This process must not be confined to simulating communication situations, but should allow the student to accomplish various tasks that are not merely linguistic. The main objective of these tasks is to prepare students for their professional career, on the one hand, and to make them assume responsibility for their learning, on the other hand. This provides them the opportunity of becoming social actors, having the competence to solve concrete tasks and be autonomous. The personal independence they gain during the intercultural learning process will prove to be very useful in their active professional life which imposes more and more demands and responsibilities nowadays.

In conclusion, from our own experience in teaching foreign languages in the Academy, the English language in particular, we stress the idea that first of all learners should become aware of their own stereotypes and overcome them in order to be able to efficiently communicate in coming in contact with individuals and groups of individuals belonging to different cultures. The encounter with a different culture can be achieved through a real dialogue based on properly perceiving the other by means of the knowledge and information gathered on that specific culture and by discovering and sharing the common values. 


\section{References}

[1] UNESCO, Intercultural Competences. Conceptual and Operational Framework, Paris, printed in the workshops of UNESCO, 2013, p.16.

[2] Deardorff, D.K., The Identification and Assessment of Intercultural Competence as a Student Outcome of Internationalization at Institutions of Higher Education in the United States in Journal of Studies in International Education, Vol. 10, No.3, pp. 241-266, 2006, retrieved from https://www.gcu.ac.uk/media/gcalwebv2/theuniversity/centresprojects/ globalperspectives/Definition_of_Intercultural_competence.pdf, 14 February 2018.

[3] The Common European Framework of Reference for Languages: Learning, Teaching, Assessment, Language Policy Unit, Strasbourg, retrieved from www.coe.int/lang - CEFR

[4] Byram, M., Gribkova, B. and Starkey, H., Developing the Intercultural Dimension in Language Teaching: A Practical Introduction for Teachers, Council of Europe, Strasbourg, 2002, pp. 11-13.

[5] Ibidem, p. 10.

[6] Lázár, I., Huber-Kriegler, M., Lussier, D., Matei, G. S., \& Peck, C. (Eds.), Developing and Assessing Intercultural Communicative Competence - A Guide for Language Teachers and Teacher Educators, Strasbourg, European Centre for Modern Languages, Council of Europe, 2007, pp.16-17.

[7] http://www.armyacademy.ro/english/einitiative.html, 16 February 2018. 